\title{
Advances in Plant Senescence
}

\author{
Kieron D. Edwards, \\ Matt Humphry and Juan Pablo Sanchez-Tamburrino \\ Advanced Technologies (Cambridge) Ltd. \\ UK
}

\section{Introduction}

Senescence is an integral component of a plant's lifecycle, which refers to changes that take place as the plant matures. A general distinction between plant senescence and animal senescence is the events observed in the animal kingdom typically steer growth while plant senescence orchestrates a massive shutdown or coordinated cell death in response to various stimuli designed to facilitate survival of the plant itself or the plant species.

In order to assist in the survival of the plant species, a sequence of tightly regulated genetic events efficiently governs a plant's death. These events are observable in a variety of plant models and in the different plant parts such as leaves, petals, reproductive organs (stamens and style), root cap, cortex and germinating seed. Leaf senescence will be the primary focus of this chapter.

A popular aspect of leaf senescence is the bright hues that can be observed on trees and plants during Autumn. The brilliant burst of colour that precedes the browning of leaves is an indication of active metabolic changes that result in the recycling or redistribution of nutrients to other parts of the plant. Evidence indicates the primary purpose of senescence in plants is for mobilization and recycling, a phenomenon that has tremendous implications for crop growth and food production.

Senescence marks the final phase of a leaf's development thereby launching degradation processes integral to the recycling and redistribution of the leaf's nutrients. Plant growth regulators, reproduction, cellular differentiation and hormone levels are internal factors that influence senescence (Thomas and Stoddart 1980; Smart 1994). Environmental stress also influences growth and can promote premature senescence. Certain parts of the plant may be sacrificed to enhance the chances of survival for the rest of the plant. Environmental cues include stress factors that adversely affect plant development and productivity; such as: drought, waterlogging, high or low solar radiation, extreme temperatures, ozone and other air pollutants, excessive soil salinity and inadequate mineral nutrition in the soil (Thomas and Stoddart 1980; Smart 1994). These environmental cues may accelerate leaf senescence by affecting the endogenous factors previously mentioned (Alegre and Munné-Bosch, 2004). Regardless of the trigger, the endogenous and exogenous signals that induce senescence appear to be coordinated through a common signalling network (Hopkins, 2007) involving the signalling molecules ethylene, jasmonic acid (JA), salicylic acid (SA) and Abscisic Acid (ABA) (Smart, 1994; Buchanan-Wollaston et al., 2005; van der Graaff et al., 2006) 


\section{Progress of senescence in plants}

The general purpose of a leaf is to gather and generate nutrients for the plant. As a green leaf grows and develops, it creates an organ packed with nutrients. When the plant no longer requires the leaf, the senescence process is induced and recycling of all the nutrients that can be remobilized occurs. Leaf death is the final stage in the process; however, death is actively delayed until all nutrients have been removed.

The dismantling of the leaf begins with the chloroplasts, the energy-generating, photosynthetic powerhouse of the plant. Not unlike another energy generating organelle (ie, the mitochondria), chloroplasts are semiautonomous and they possess their own genome with its inherent transcriptional and translational machinery. Gradually the chloroplasts shrink and transform into gerontoplasts, an artefact characterised by the disintegration of the thylakoid membranes and accumulation of the plastoglobulin (Friedrich and Huffaker, 1980; Mae et al., 1984). The process of breaking down the chlorophyll is so pronounced that chlorophyll loss and the associated yellowing of the leaves are commonly used as indicators of plant senescence (Noodén et al., 1997). Control of the process is so tightly regulated that experiments demonstrating the reversibility of senescence have shown that the chloroplasts can recover structural features, re-synthesize chloroplast proteins and re-commence photosynthesis (Thomas and Donnison, 2000; Zavaleta-Mancera et al., 1999).

Degradation and remobilization of the chloroplast proteins and RNA contribute nitrogen and other nutrients for seed growth (Wittenbach, 1978). The mechanisms governing degradation of the chloroplast are not completely understood and there are competing theories about where proteins are degraded; for example they may be degraded locally within the chloroplast or in a centralized vacuole for degradation (Hortensteiner and Feller, 2002). Findings that support the possibility that the photosynthetic machinery is degraded in situ by the chloroplast include the presence of chloroplast enzymes, which are localized hydrolases that catalyze the initial steps of chlorophyll breakdown. (Hortensteiner, 2006). Proteases of the Clp, FtsH and DegP families are also expressed in chloroplasts and representative genes for these proteases are up-regulated in senescing leaves (Sokolenko et al., 1998; Nakabayashi et al., 1999; Itzhaki et al., 1998; Haussühl et al., 2001). Despite this observation, chloroplastic proteases are unlikely to account for the degradation of most photosynthetic proteins (eg, Rubisco) during senescence. Senescence-associated vacuoles, with strong proteolytic activity, have been identified in senescing tissue and likely also contribute towards the degradation of soluble photosynthetic proteins (Hensell et al., 1993; Comai et al., 1989).

Chloroplast degradation is followed by lipid, protein and nucleic acid degradation. Membrane integrity and cellular compartmentalisation are maintained until the latter stages of leaf senescence (Lohman et al., 1994; Smart, 1994; Pruzinska et al., 2005). A decline in photosynthesis during senescence may result in sugar starvation leading to the activation of conversion of lipids to sugars. Thylakoid breakdown leads to release of lipids, which are known to be converted to sugars through the glycoxylate cycle (Buchanan-Wollaston and Ainsworth, 1997; Kim and Smith, 1994). The sugars produced by conversion of large amounts of lipids may be in excess to that required for respiration of the senescing leaves and this excess may be exported to other growing and demanding parts of the plant. It appears that the expression of genes for the enzymes participating in the process of gluconeogenesis for production of sucrose play an important role during senescence as the 
genes responsible for synthesis of the enzymes involved in gluconeogenesis are reported to be significantly expressed during this time (Buchanan-Wollaston and Ainsworth 1997; Kim and Smith, 1994).

Leaf senescence also results in the breakdown of nucleic acids to purines and pyrimidines, which ultimately degrade to small and transportable carbon and nitrogenous compounds that are transported to growing parts of the plant (Buchanan-Wollaston and Ainsworth, 1997). In addition to mobilization of carbon and nitrogen, other nutrients like sulphur and metallic ions are also known to be transported from senescing leaves. Sugar content can also be modified at the onset of senescence. Generally crops under a limited nitrogen nutrition and high light regimen undergo early senescence and this is usually accompanied by an incremental rise of sugar levels in the leaves. Sugar has been suggested to trigger a senescence response based on gain or loss function experiments with hexokinase genes, principal regulators of a glucose signalling pathway (van Doorn, 2008).

\section{Regulation of senescence and potential for biotechnology}

Before the advent of modern biotechnology, which enabled scientists to commence deciphering the relationship between genes and life, senescence was perceived as an uncoordinated collection of events resulting in the metabolic and physiological changes to plant organs described above. The study of plant genetics, genomics, proteomics and more recently metabolomics have altered this perception and demonstrated that the process is dynamic and well organised. Below, a few examples are provided to emphasize the importance of a better understanding of plant senescence and the consequent potential of applications derived from that understanding.

Several techniques and different plant models have been employed in the pursuit of understanding the genetic mechanisms underlying the changes in gene expression associated with senescence. The process of senescence is initiated in source tissues prompting dramatic changes in gene expression, during which genes involved in basic metabolism, including photosynthesis and protein biosynthesis, are down-regulated while those involved in programmed cell death and stress response and/or encoding various hydrolytic enzymes are up-regulated (Hopkins et al., 2007; Lim et al., 2007). Not surprisingly the initial discoveries involving Senescence Associated Genes (SAGs) were made in the model plant Arabidopsis (Arabidopsis thaliana) by methods including differential display (Lohman et al. 1994), senescence-specific enhancer trap line screening using a range of senescence promoting factors (He et al., 2001), subtractive hybridization (Gepstein et al., 2003) and microarray experiments (Andersson et al., 2004). Many of the genes expressed during senescence of tissues encode hydrolytic enzymes that are capable of disassembling the ultra-structure of the cell and the breakdown of macromolecules (Smart, 1994; Griffith et al., 1997; Watanabe et al., 1994). In addition, a large number of transcription factors, as well as genes encoding carbohydrate and nitrogen-mobilising enzymes, nucleases and stressresponsive proteins, have been found to exhibit increased expression in senescing leaves (Buchanan-Wollaston and Ainsworth, 1997; Comai et al., 1989; Kim and Smith, 1994). The gene expression changes and biological processes that are up- and down-regulated during senescence as indicated by such studies, have been reviewed elsewhere (Guo and Gan, 2005), so will only be touched on in this review. What is more in the scope of this review are the potential implications that senescence has for plant biotechnological applications. 
In addition to the conventional use of crops as food sources, innovations continue to expand the role of crop species in society. With these changes, the importance of understanding senescence becomes even more significant. Crops and trees are being developed as an alternative fuel source. Plants are also being integrated into the production of pharmaceutical ingredients and complex protein therapies such as vaccines (Lossl and Waheed, 2011). These and other innovative uses for plants make obtaining a greater understanding of senescence a necessary step for harnessing the influence of senescence on the plant lifecycle and reducing the impact this has on product yields and stability. The SAGs found through Arabidopsis investigations have provided a reference point for studies in other plant species, providing the potential to translate fundamental understanding into applied tools. Delaying the onset of senescence could increase the production of the desired plant product. This may be of particular interest in plastid expression systems (reviewed in Day and Goldschmidt., 2010), given that the chloroplast degradation occurs at a relatively early stage of senescence.

\subsection{Populus tremula and bio fuel}

As suggested above, crops are being developed for alternative applications including bio fuels and paper production. The deciduous Aspen tree species Populus tremula is one such plant being developed for alternative fuel production. By comparing expressed sequence tag (EST) libraries generated from young fully-expanded leaves to leaves harvested immediately prior to visible signs of senescence, Bhalerao et al., (2003) identified P. tremula homologs for many known Arabidopsis SAGs. Altering the expression of these SAGs may have an effect on dormancy in this species with possible implications on the wood yield from these trees.

The onset of growth cessation and dormancy represents a critical ecological and evolutionary trade-off between survival and growth in most forest trees. Without this dormant stage nutrients stored in green leaves would be lost to frost, which would impact growth in the spring. Tight regulation over the timing of senescence is thus important. Latitudinal clines influence the critical photoperiod for onset of bud set (dormancy) and leaf senescence in Aspen (Fracheboud et al., 2009). This cline in dormancy was associated with multiple alleles of PHYTOCHROME B2 (PHYB2), a photoreceptor that is related to light perception and light input to the circadian clock (the internal timing mechanism of the plant). The circadian clock enables the plant to co-ordinate its endogenous activities with the external environment to maximise the effectiveness of its activity. These activities occur on a daily basis, such as the timing of photosynthetic gene expression (Harmer et al., 2000, Edwards et al., 2006), and on an annual basis when measuring photoperiod and coordinating activities such as transitions to flowering, senescence or dormancy (reviewed in Jackson, 2009). Indeed, previous experiments suggest more accurate timing by the clock in relation to the external environmental cycles also has the potential to improve crop yields (Dodd et al., 2005). Such regulation governing the timing of critical events is relevant to all crop species grown in temperate climates. In the case of senescence, utilising regulatory mechanisms such as the circadian clock has the potential to alter the timing of this process with benefits to both wood production (reduced loss of nutrients to frost) as well as, for example, increasing the length of the grain filling period in other crops. 


\subsection{Impact on yield}

During whole plant senescence, fixed carbon and nitrogen are mobilized to reproductive or storage organs, which are harvested for human consumption (Vierstra, 1996; Hopkins et al., 2007; Lim et al., 2007). The process of senescence impacts all crop species and so the increased understanding of the tight regulatory mechanisms that control the process could potentially have an immeasurable impact on the world's agricultural production. Whole plant senescence plays a key role in remobilizing and transferring nutrients into the vegetative tissue and eventually to grain. The grain filling period is a critical period because many processes can influence the final grain yield (Yang and Zhang, 2006). For example, delaying whole plant senescence can be achieved by heavy use of fertilizer or development of a stay-green phenotype produced using a genetic or transgenic strategy. Extending or delaying senescence is believed to augment the grain filling stage thereby increasing grain yield. Contrarily, stresses, such as drought, induce early senescence, prompting the reduction of photosynthesis and shortening the grain filling period (Gregerson et al., 2008) and thus having the opposite affect on yield. Ectopic expression of SAG101, a protein with acyl hydrolase activity, has been shown to cause precocious senescence in both attached and detached leaves of transgenic Arabidopsis plants (He and Gan, 2002). Antisense expression of the gene, resulting in repression of the endogenous genes expression, was shown to cause a delay in the onset of senescence (He and Gan, 2002). Utilising genes such as SAG 101 to induce a stay-green/delayed senescence phenotype could potentially be employed in biotechnological strategies to increase yields in crops such as wheat.

Effective recycling of nutrients could have a massive impact on crop yields. Recycling of carbon and nitrogen during senescence involves the sequestering of cytoplasm and organelles into special autophagic vesicles. These vesicles deliver their contents to the vacuole (or lysosome) for breakdown by localized hydrolases (Thompson and Vierstra, 2005; Bassham, 2007). The breakdown products are either consumed by the host cell or transported to other tissues and organs. Under normal growth conditions, autophagy takes place at a basal level. The process ramps up in response to nutritional demand, biotic or abiotic stresses, and senescence. Autophagy plays an important role in the proper recycling of nutrients especially as a plant scavenges available nutrients from storage tissues and older senescing leaves.

When a pathway has been highly conserved evolutionarily, other organisms can provide the reference point for understanding a system in plants. The genes associated with autophagy discovered in yeast, enabled investigators to identify homologous genes in Arabidopsis and, subsequently, in rice and maize. Genome searches of Arabidopsis identified a collection of proteins structurally and functionally related to many of the ATG components present in yeast (Thompson and Vierstra, 2005; Bassham, 2007). In an effort to determine the importance of autophagy to crop plants, investigators at the University of Wisconsin, using the Arabidopsis as a reference, described a collection of components that participate in the ATG8/12 conjugation cascades in both rice (Oryza sativa) and maize (Zea mays). Remarkably, all components required for ATG8/12 conjugation in yeast and Arabidopsis (Ohsumi, 2001; Thompson and Vierstra, 2005) were identified in both rice and maize suggesting that the pathway is highly conserved. The group went on to greater characterize the expression of the maize ATG genes (Chung et al., 2009). The investigators observed an increase in ATG transcripts during leaf senescence and under nitrogen and fixed-carbon limiting conditions. The results indicate that the highly conserved process of autophagy plays a key role in 
nutrient remobilization with some variations unique to maize. The description of the maize ATG system provides a set of molecular and biochemical tools to study autophagy in this crop under field conditions (Chung et al., 2009). The same is true for rice (Ohsumi, 2001; Thompson and Vierstra, 2005). This type of knowledge may help to reveal important control points in autophagy that could be manipulated in both food and bio fuel crops to enhance nutrient use efficiency or to better allocate carbon and nitrogen to specific organs for improved yield.

In addition to highly conserved genes, specific genes or gene families that can also be employed to influence grain quality and yield. Uauy et. al., (2006) cloned a Quantitative Trait Locus (QTL) associated with increased grain protein, zinc, and iron content known as Gpc-B1. The ancestral wild wheat allele encodes a functional NAC transcription factor (NAM-B1) that accelerates senescence and increases nutrient remobilization from leaves to developing grains. In contrast, modern wheat varieties carry a non-functional NAM-B1 allele. Reduction in RNA levels of the multiple NAM homologues by RNA interference delayed senescence by more than three weeks and reduced wheat grain protein, zinc, and iron content by more than $30 \%$. Other examples of specific genes having an effect in senescence include the cytokinin synthesis gene IPT, which has been shown to delay leaf senescence (Gan and Amasino, 1995), thereby providing the potential to increase seed setting time and yield, but the affect this has on nutritional value must also be considered.

\subsection{Ripening}

Although the main focus of this review relates to leaf senescence, fruit ripening is an aspect of plant senescence that is also of global significance. The timing of ripening is a key consideration when harvesting and transporting fruit to market. Successful efforts to control fruit ripening are based on either reducing the biosynthesis of the plant hormone ethylene or slowing down the rate of fruit softening by targeting the genes involved in cell wall modification (Causier et al., 2002). The Flavr Savr tomato is an example of an early attempt to slow ripening using the latter strategy. Researchers at Calgene hoped to slow the ripening process of the tomato by engineering in an antisense gene to interfere with production of the enzyme polygalacturonase (Weasel, 2009). The enzyme normally degrades pectin in the cell walls and results in softening.

More recently, investigators have attempted to characterize the $\mathrm{N}$-glycan processing enzymes and their role in during non-climacteric fruit softening. The plant hormone ethylene does not influence ripening of non climacteric fruits and different genes need to be targeted for the different categories of fruits (Causier et al., 2002). Two ripening-specific Nglycan processing enzymes, a-mannosidase ( $\mathrm{a}-\mathrm{Man}$ ) and $\beta$-D-N-acetylhexosaminidase were identified in the fruit capsicum (Capsicum annuum, Ghosh et al., 2010). Using RNA interference to suppress production of such enzymes has the potential to improve the shelf life of fruits, with obvious implications for improved food stability/storage.

\section{A view on tobacco biotechnology and senescence}

Tobacco is different from many of the crops discussed above because the organ harvested for human use is the leaf rather than reproductive organs (i.e. seed and fruit). The smoke generated during the burning of tobacco is a complex mixture of thousands of chemicals (Rodgman and Perfetti, 2008). Research to identify and characterise the harmful components 
present in tobacco smoke is ongoing, with lists such as the 44 Hoffmann analytes, being produced by researchers and public health organisations (Hoffmann and Wynder 1967; Baker, 1999; Norman, 1999; Borgerding and Klus, 2005). A major focus of tobacco research is related to lowering the levels of these chemicals from smoke in an effort to reduce the harmful effects associated with tobacco use (for an overview of such research the scientific website of British American Tobacco [BAT] n.d.). Understanding the regulation and effect of senescence on tobacco leaf chemistry could be of particular importance to these traits since it is following the onset of senescence that 'ripe' tobacco leaves are harvested.

\subsection{Gene expression changes in senescing tobacco leaves}

The availability of microarrays has considerably increased the extent to which differentially expressed genes can be identified and this line of research provides valuable insights into the identification of senescence related genes. High throughput analysis makes it possible to monitor changes in gene expression throughout the lifecycle of a plant. Researchers from Advanced Technologies (Cambridge) have recently described the generation of a tobacco (Nicotiana tabacum) custom expression array (Edwards et al., 2010). This array was used to develop the Tobacco Expression Atlas (TobEA), a map of gene expression from multiple tissues sampled throughout the life cycle of the tobacco plant which can be used as a reference data set for plant researchers. The expression data is freely available via the Solanaceae Genomics Network (SGN), a web based genomic resource for plants of the Solanaceae family (Mueller et al., 2005). Studying the changes in gene expression has the potential to identify targets that enable modifications or changes to leaf constituents in tobacco using transgenic or non-transgenic (e.g. molecular breeding) approaches.

Included in the TobEA study was a set of leaves from different positions that were categorised into either green (sink) or four distinct senescent (source) leaves, based on the average amount of yellowing and chlorosis across the leaf (Figure 1A; data not shown). Analysis of the gene expression changes in the tobacco leaf series suggested that tobacco showed similar changes during the progression of senescence as Arabidopsis leaves. For example the defence-associated phytohormone SA is known to play a role in developmental leaf senescence in Arabidopsis, with mutants and transgenic lines defective in the SAmediated signalling pathway exhibiting delayed senescence (Buchanan-Wollaston et al., 2005; Morris et al., 2000). A significant over-representation of genes associated with systemic acquired resistance and the SA-mediated signalling pathway was observed in the upregulated genes in the TobEA dataset, including presumptive orthologues of ENHANCED SUSCEPTIBILITY 1 (EDS1) and PHYTOALEXIN DEFICIENT 4 (PAD4), central regulators of SA-mediated defence (Figures 1H and I; Feys et al., 2005; Morris et al., 2000).

There was also significant over-representation of Gene Ontology categories associated with defence against fungal pathogens as well as cell death and innate immune responses in leaves at more advanced stages of senescence. These included a homologue of the Arabidopsis basic chitinase PR3 (Verburg and Huynh 1991) in addition to other components of plant immunity/defence. This supports the growing evidence that pathogen defence and senescence share common components (Quirino et al., 1999; Feys et al., 2005), presumably largely via the use of similar signalling pathways leading to accumulation of reactive oxygen species and cell death (Yoshida, 2003). 

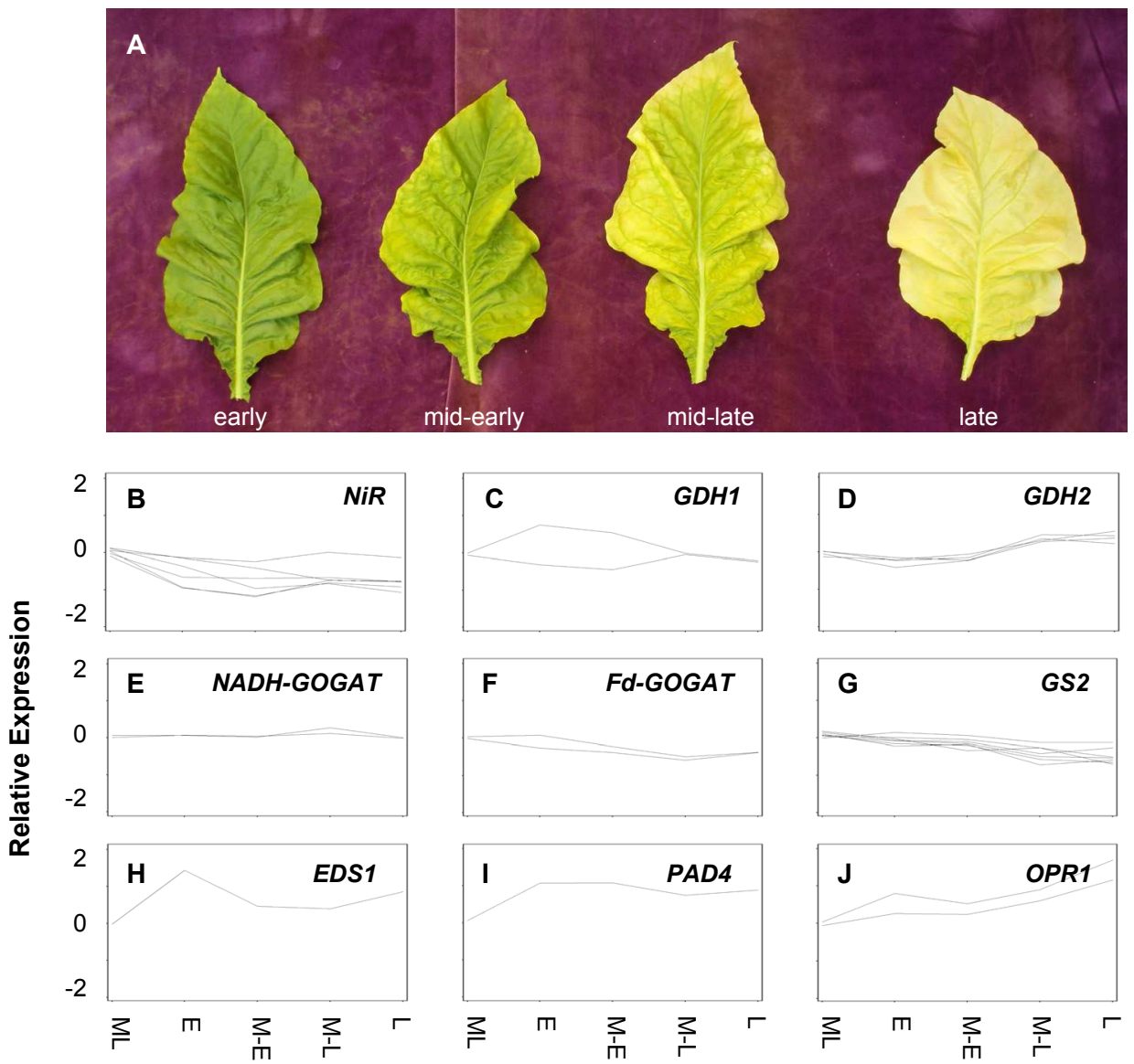

\section{Leaf Type}

Fig. 1. Gene expression changes in tobacco source and sink leaves

(A) A sink to source series of leaves harvested from different positions on tobacco plants included in the Tobacco Expression Atlas and categorised as early- (E), mid-early- (M-E), mid-late- (M-L) and late- (L) senescent leaves based on level of Chlorosis (TobEA; Edwards et al., 2010). (B-J) Log expression data for selected transcripts associated with Nitrogen metabolism and plant hormone responses shown (See top right of each plot for transcript identification). Expression data was pre-processed with RMA and normalised against mature leaf (ML) samples showing no visible signs of senescence (also included in the TobEA data set). Differentially expressed genes from the sink-source series versus the mature leaf control were identified by one-way analysis of variance with Tukey HSD post hoc testing in GeneSpring GX 10 (P < 0.05). Gene ontology analysis of the up- and downregulated genes in each condition (described in main text) were analysed by a custom script as described previously (Edwards et. al., 2010). 
In addition to SA, several other hormone pathways were identified as being overrepresented in the TobEA leaf senescence dataset including Jasmonic acid (JA). JA is known to have a role in developmental senescence, with both levels of JA itself and a number of JA biosynthetic genes found to increase during senescence (He et al., 2002). A similar response was observed in the developmental senescence dataset, with 12-OXOPHYTODIENOATE REDUCTASE (OPR) family members being induced and an overall over-representation of genes involved in JA-meditated induced systemic resistance (Figure 1J; data not shown).

Ethylene is also known to play a role in promoting the onset of senescence (Grbic and Bleecker, 1995). Interestingly however, ethylene-mediated responses were not significantly over-represented in the TobEA data, suggesting that either ethylene is not as important in senescence of tobacco or that changes in this pathway are occurring post-transcriptionally. Stress can induce a senescence response in plants and one of the principal mediators of the stress response is the phyto-hormone Abscisic Acid or ABA (Smart 1994). ABA is a participant in drought (water) and cold stress responses (Wingler and Roitsch, 2008) and directly influences the sugar accumulation in response to stress. Interestingly, ABA will induce senescence during drought stress whereas it will delay senescence during cold stress (Xue -Xuan et al., 2010). In the TobEA data the ABA metabolic processes were significantly reduced late in senescence, the reason for which is unknown (data not shown).

Cytokinin levels in senescing leaves are though to play a key role in developmental leaf senescence, with both external and endogenous application resulting in delayed senescence (Smart 1994). This is largely reflected in the transcriptional responses to developmental senescence in Arabidopsis (Buchanan-Wollaston et al., 2005), as well as in the TobEA data, where cytokinin response processes were significantly down-regulated compared to controls.

Interestingly, phenylpropanoid biosynthesis was identified as a significantly down-regulated process the TobEA data. It would be expected that increased production of photo-protective phenylpropanoids, flavonoids in particular, would be observed during developmental leaf senescence, due to increased light stress during the degradation of chlorophyll (BuchananWollaston 2005). Indeed, Buchanan-Wollaston et al., (2005) found a number of flavonoid biosynthesis genes had increased expression during developmental senescence.

Consistent with the phenotypic observations of the leaves themselves (Figure 1A), there was an enrichment of genes associated with photosynthesis being down-regulated in the TobEA data. This was accompanied by significant number of down-regulated genes associated with chloroplast components as well as responses to red, far-red and ultraviolet light stimuli. Over all the data suggest that similar processes occur during leaf senescence in Tobacco as in Arabidopsis and highlights the potential to translate findings in model species to biotechnological applications in other crops including Tobacco.

\subsection{Nitrogen metabolism and harm reduction}

Environmental and economic issues combined have increased the need to better understand the role and fate of nitrogen in crop production systems. Nitrogen is one of the most important nutrients recycled by the plant during senescence, with up to $90 \%$ recovered from the leaf during this process (reviewed in Liu et al., 2008). Adding nitrogen to the soil increases crop yields and delays senescence, whereas a reduced fertilizer regimen generally triggers early whole plant senescence in crops due to low nitrogen. A strong coordination of 
nitrogen-uptake, assimilation and remobilization is required for a beneficial grain filling stage (Hortensteiner and Feller 2002). The period that follows flowering can be critical in this process. Some crops, such as maize (C4 photosynthesis), use Nitrogen sourced both from the root's uptake and assimilation of $\mathrm{NO}_{3}$ - as well as nitrogen remobilized during leaf senescence. Other crops, such as oil seed rape, primarily rely on the remobilization of nitrogen from leaves, making these crops more dependent on the senescence process (Coque et. al., 2008). When nitrogen inputs to the soil system exceed crop needs, there is a possibility that excessive amounts of nitrate $\left(\mathrm{NO}_{3}^{-}\right)$may enter either ground or surface water causing a detrimental effect on the environment.

In the case of tobacco, a greater understanding of the metabolism of nitrogen could also be applicable in an attempt to reduce the harmful constituents contained in cigarettes. One class of chemicals likely to feature in any future legislation of the tobacco industry is the Tobacco Specific Nitrosamines (TSNAs); 4-(N-methlynitrosamino)-1-(3-pyridyl)-1-butanone (NNK), Nnitrosonornicotine (NNN), N-nitrosoanabasine (NAB) and N-nitrosoanatabine (NAT).

TSNAs are principally formed by the nitrosation of tobacco alkaloids during the curing (drying) of tobacco leaf (Burton et al., 1989; Burton et al., 1994; Hoffmann et al., 1994; Spiegelhalder and Bartsch, 1996). Several studies have demonstrated a significant correlation between nitrite (formed by the microbial reduction of nitrate during curing) and TSNA levels in tobacco leaf, leading to the proposal of nitrite as the key nitrosating agent for TSNA formation (Burton et al., 1989; Fischer et al., 1989; Burton et al., 1994; Spiegelhalder and Bartsch, 1996; Wu et al., 2005). Curing conditions (including airflow, temperature and humidity) and their affect on microbial activity have been shown to affect the levels of TSNAs formed (Burton et al., 1989; Burton et al., 1994). Further understanding the nitrogen metabolism of tobacco could aid in reducing the potential for accumulating nitrosating agents during the curing process helping to limit the formation of TSNAs, and potentially reducing the levels of these toxicants in tobacco smoke.

Figure 2 shows a summary of the nitrogen assimilation pathway in plants. Plant nitrogen assimilation primarily occurs in mesophyll cells and involves the reduction of nitrate (taken up by the root) into ammonia by the enzymes-Nitrate Reductase (NR) and Nitrite Reductase (NiR; Figure 2). The ammonia is subsequently assimilated into the amino acids glutamine (gln) and glutamate (glu) via the cyclic action of Glutamine Synthetase (GS) and Glutamine-2-oxoglutarate aminotransferase (GOGAT; Figure 2; Lea and Miflin 1974).

Nitrogen assimilation is regulated by many factors, including the availability of sugars and other metabolites and also shows significant variation over the diurnal cycle (reviewed in Stitt et. al., 2002). The expression and activity of genes involved in nitrogen reduction and assimilation have previously been shown to be down-regulated in tobacco leaves at more advanced stages of senescence (Mascluax et. al., 2000). Masclaux et. al, compared leaves from different positions on mature tobacco plants and showed that there was a switch between nitrogen assimilation and nitrogen recycling from sink to source leaves at more advanced stages of senescence. The leaf series included in the TobEA microarray data set described above is similar to the leaf series tested by Masclaux et. al (Masclaux et. al 2000). Expression of nitrogen metabolism genes in the TobEA leaves compared with fully expanded mature leaves showing no visible signs of senescence (also included in the TobEA data), demonstrated consistent results with Masclaux et al., (2000; Figure 1). 


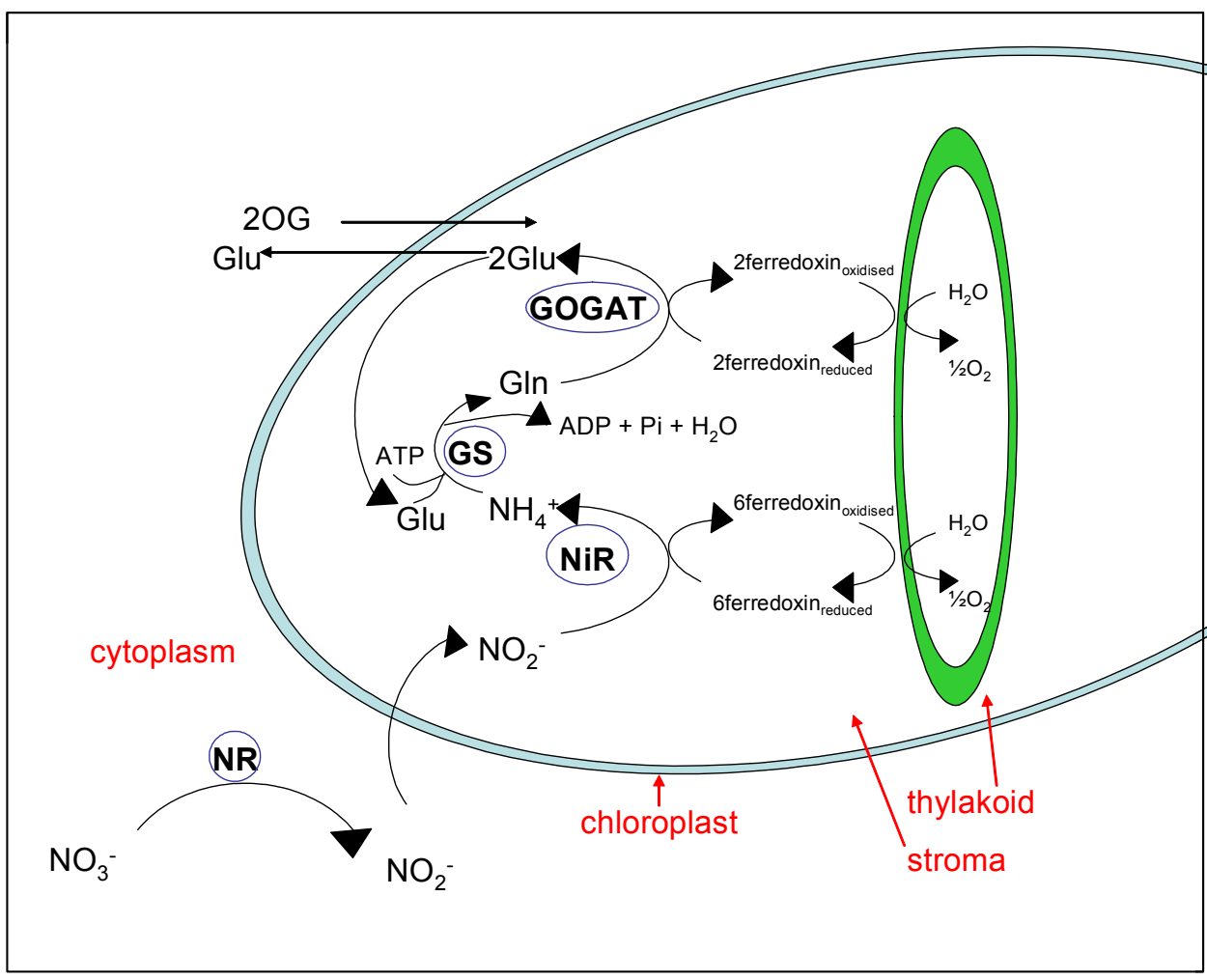

Fig. 2. Primary nitrogen assimilation in plants.

Representation of the primary nitrogen assimilation pathway in a mesophyll cell (modified from Mohr and Schopfer, 1994), showing reduction of Nitrate to Nitrite and then Ammonia by NR and NiR respectively and subsequent incorporation of nitrogen into gln and glu by the cyclic activity of the enzymes GS and GOGAT.

No probe sets for NR could be identified on the tobacco array, so the reduction in expression of this gene shown by Masclaux et al., (2000) could not be confirmed in the TobEA data. However, a decrease in NiR expression over the leaf series was shown, supporting a reduction in nitrogen fixation activity in the older leaves (Figure 1B). The ammonia generated by NR and NiR activity is incorporated into amino acids by the GS-GOGAT cycle. Plants have two types of GOGAT; ferredoxin dependent (Fd-GOGAT) and NADH dependent (NADH-GOGAT). Similarly GS genes can be subdivided into cytosolic and plastidic forms (GS1 and GS2 respectively). Fd-GOGAT functions in concert with GS2 and NADH-GOGAT is associated with GS1. In previous studies (Buchanan Wollaston 2005, Lin and $\mathrm{Wu} 2004)$, GS1 and NADH-GOGAT have demonstrated a co-ordinated increase in expression in Arabidopsis. GS1 expression was previously shown to be induced in tobacco source leaves, whereas GS2 transcripts were shown to be down regulated (Masclaux et al., 2000). No tobacco orthologues for GS1 were identified on the tobacco microarray and transcripts for NADH-GOGAT did not demonstrate changes in expression over the TobEA 
dataset (Figure 1D). However, consistent with previous results, GS2 transcripts were down regulated over the series of leaves (Figure 1C). A similar pattern of expression was also shown by tobacco Fd-GOGAT transcripts, supporting the proposed coordinated regulation and activity for these genes and a reduction of chloroplastic nitrogen assimilation in source leaves (Figures $1 \mathrm{C}$ and $\mathrm{E}$ ).

Glutamate dehydrogenase (GDH) catalyses a reversible reaction adding or removing amino groups from glutamate. It has been proposed that the principal role of GDH is the deamination of glutamate in order to maintain a homeostatic balance of this amino acid that is thought to play a key role in the cross talk between the carbon and nitrogen assimilation pathways (Labboun et al., 2009). It has also been suggested that GDH amination may play a role in replacing glutamine synthetase (GS) activity in nitrogen assimilation within source leaves, which is lost during senescence (Masclaux et al., 2000). Previous studies have shown an increase in GDH expression in source leaves (Masclaux et al., 2000). Consistent with this, tobacco GDH2 orthologs did show an increase in expression over the series; however, little change was shown by GDH1 (Figures $1 F$ and G).

Changes in the expression of genes involved in nitrogen assimilation shown by the leaves suggested that nitrogen metabolism was altered in source leaves towards remobilisation of the nitrogen resources to sink leaves. Consistent with this, gene ontology analysis of clusters of genes showing up-regulation in leaves demonstrating more advanced senescence revealed over representation of genes with functions related to proteolysis, the proteosome and endoplasmic reticulum associated protein catabolism. Increased understanding of the regulation of senescence in tobacco leaves could potentially help to limit the content of nitrate (and other nitrosonating agents) in harvested leaves prior to curing. This may augment efforts to reduce the levels of TSNAs in tobacco smoke; however, the study of senescence also provides other tools to facilitate TSNA reduction.

The main focus of agricultural research has been towards increased yield along with other agronomic traits. It is apparent in some crops that this has led towards an ignorance of flavour and texture components (as well as the associated nutritional value). Research is currently ongoing to understand and ultimately adjust the metabolic content of crops, such as those found in tomato, that contribute towards flavour and nutrition. This orientation toward flavour highlights the realisation that a perceived consumer benefit and consumer acceptance is becoming a more important driver in the development of new crops (Klee 2010). As indicated above, tobacco crops can be cured by multiple methods and the resulting leaf, or grades are blended together to produce the constituents of a cigarette. Dependent on the design, air cured tobacco typically only constitutes up to $30 \%$ of the blend in a cigarette, the rest being mainly made up of flue cured leaf (see Davis and Nielsen 1999 for a description of tobacco agronomy and chemistry). The conditions during air curing can lead to the formation of high levels of TSNAs. Thus, removing such grades from the blend could have beneficial affect on the overall level of TSNAs in the product. However, air cured grades make a significant contribution to the overall flavour of the cigarette, so the resulting product may not be consumer relevant and thus have no impact on harm reduction efforts. Replacing air cured grades with other grades that replace the flavour characteristics of these grades, but without the inherent higher levels of TSNAs provides one potential solution. 

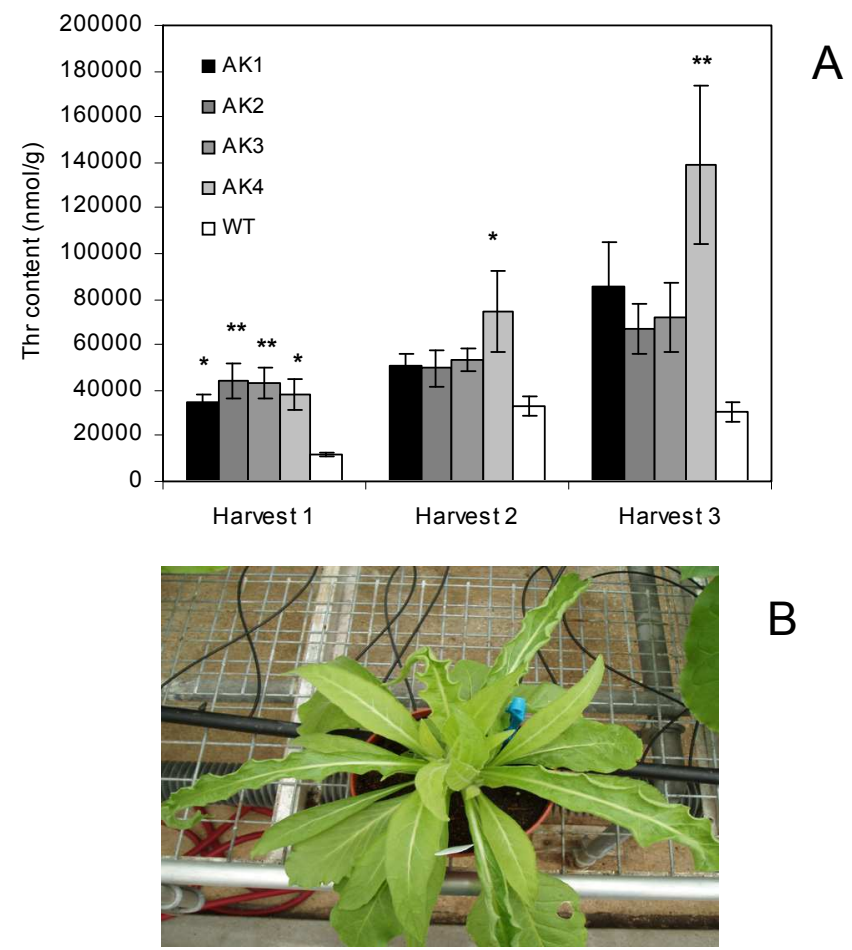

B

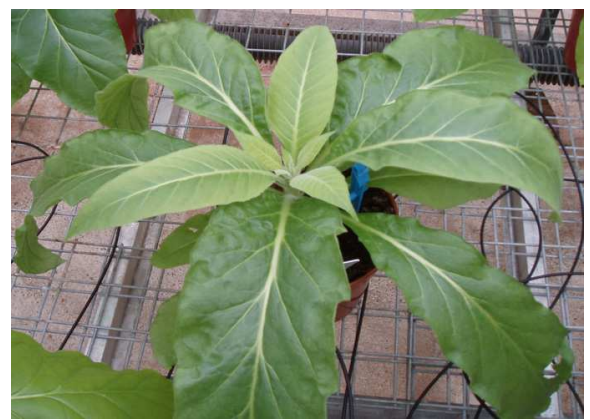

C

Fig. 3. Increased threonine production in tobacco leaves

Levels of threonine (nano moles per gram of cured leaf) for wild type tobacco and four independent transgenic tobacco lines expressing a mutated form of the Arabidopsis Aspartate Kinase AK:HSD (See inset key for line identification). Bars show mean threonine levels and error bars represent Standard Error of the mean. Leaves were taken from three harvest positions from the bottom to the top of the plant (Harvest $1-3$ ). Asterisks represent significant difference between transgenic lines and WT for each harvest position based on one way analysis of variance with Tukey HSD post hoc testing $\left({ }^{*} P<0.005\right.$, ** $\left.P<0.001\right)$. Constitutive expression of the same gene results in increased threonine levels in tobacco leaves (data not shown), but results in reduced growth and altered morphology in (B) transgenic plants compared to $(\mathrm{C})$ wild type plants. 
Amongst other differences, air cured tobaccos tend to have lower levels of sugars and an altered balance of free amino acids compared to flue cured tobacco leaf (Davis and Nielsen 1999). Threonine (thr) is one of the amino acids observed in higher levels in air cured leaf compared to flue cured, indicating it may contribute towards the flavour and aroma of the tobacco. Within the leaf, the biosynthetic pathway leading to production of thr is tightly regulated by a negative feedback control loop. In the case of feedback inhibition the endproduct, in this case thr, competitively inhibits the activity of the bifunctional enzyme ASPARTATE KINASE (AK) (EC 2.7.2.4) -HOMOSEREINE DESATURATE (HSD) (EC 1.1.1.3) and consequently blocks the enzymatic processes leading to its own synthesis (Shaul and Galili,1993). Disabling the enzyme that switches off thr production would prompt a greater accumulation of the compound, but, if the accumulation takes place too early in the plant's life cycle, the fitness of the plant is severely compromised (Fig 3A: data not shown). To overcome this obstacle, the promoter of the senescence associated gene SAG12, identified in Arabidopsis (Lohman 1984), was used to drive expression of mutated forms of AK:HSD gene from Arabidopsis in tobacco. Elevated leaf thr levels were achieved in the modified plants without compromising the plant's fitness (Fig $3 \mathrm{~B}$ and C). If the increase in thr results in an increase of the air cured 'flavour' in the tobacco, then such an approach could provide the potential to reduce the amount of this tobacco in the blend resulting in an associated reduction in the TSNA levels.

Optimising the timing and absolute level of expression by selecting other senescence associated promoters from tobacco could help to increase the yield of thr present in harvested leaves. Such promoters, could also be used to up, or down regulate the synthesis of other target flavour or toxicant precursors at the correct stage in the plant's life cycle to maximise the target phenotype, with limited effect on the growth of the plant.

\section{The translational nature of innovation}

Nature has long been an infinite resource for the purpose of scientific discovery. Consequently, the study of plant senescence possesses immeasurable potential for increasing the understanding of the plant kingdom and the technological application of that knowledge. Genomics and the subsequent disciplines of proteomics and metabolomics have provided a complete reorientation toward the ways in which plants are designed to facilitate preservation of their own species. Thousands of genes that increase expression during leaf senescence have been isolated from a number of crop varieties; such as: Arabidopsis, wheat, tomato, maize, rice, and tobacco; these are just the tip of the iceberg.

Many of the recent advances in the understanding of plants (and organisms in general) can be attributed to the exponential increase in the sequencing and bioinformatics capacity of the world's research communities, coupled with numerous initiatives being driven by governments, academics and the private sector. Advances in gene sequencing techniques have made it possible to decipher entire genomes and high throughput microarray analysis and other techniques make it possible to monitor changes in a plant over time. By comparing what genes are switched on and off as a plant senesces, a collection of SAGs have already been discovered. Tracing the homology of conserved sequences through the evolutionary line, not only has facilitated the discovery of more SAGs, it has helped to elucidate the dynamics of an entire senescence-associated biosynthetic pathways such as ATG8/12. Comparative studies between species not only reveal similarities, researchers inevitably find unique differences specific to the plant variety and species contributing even more information to the pool. 
Alternatively, Biotechnological tools (i.e. gene vectors) and progressive strategies, such as molecular breeding, make it possible to apply research findings to addressing modern challenges. For example, an understanding of the tight regulation of senescence can be applied to modify the grain filling stage in an appropriate plant organism in order to increase the grain yield (harvest index). Altering the senescence stage to enhance remobilization or delay senescence through stay-green strategies (the most successful approaches being enhancing endogenous cytokine pathways and reducing ethylene production or perception) has become a routine approach to increasing productivity (Gan and Amasino 1995). Similarly senescence promoters and pathways have already been used to augment the flavour and deter the spoilage of products such as tomatoes and augment the nutrition of wheat.

Development of transcriptional data-sets such as the one we describe in tobacco will continue to facilitate discovery and drive innovation. Understanding how plants use nitrogen could potentially lead to improving nitrogen strategies that increase productivity of the plant and enhance the sustainability of farming. In the case of tobacco, knowledge of senescence and nitrogen metabolism is being applied to altering the leaf to decrease the level of target chemicals found in tobacco smoke. The extent to which plant genome initiatives are being undertaken by governments, academics and industrial partners will serve to ensure that genomics and the related branches of research will continue to contribute new tools, including genes and pathways that can regulate senescence and applications that promise to have an impact on modern society.

\section{Acknowledgement}

We would like to acknowledge Susie Davenport and Gwendoline Leach for the provision of data and Barbara Nasto for assistance with the writing/editing of this manuscript.

\section{References}

Alegre, H., \& Munné-Bosch S. (2004). Drought-induced changes in flavonoids and other low molecular weight antioxidants in Cistus clusii grown under Mediterranean field conditions, Tree Physiology, 24(11) pp 1303-1311

Andersson, A., Keskitalo, J., Sjödin, A., Bhalerao, R., Sterky, F., Wissel, K., Tandre, K., Aspeborg, H., Moyle, R., Ohmiya, Y., Bhalerao, R., Brunner, A., Gustafsson, P., Karlsson, J., Lundeberg, J., Nilsson, O., Sandberg, G., Strauss, S., Sundberg, B., Uhlen, M., Jansson, S., \& Nilsson, P. (2004) A transcriptional timetable of autumn senescence, Genome Biology, 5: R24

Baker, R. R. (1999) Smoke chemistry, In: Tobacco Producton, Chemistry and Technology, Davis D L \& Nielsen M. T., pp. 398-439, Blackwell Science Ltd., ISBN 0-632-04791-7, Oxford

Bassham, D. C. (2007) Plant autophagy--more than a starvation response, Current Opinion in Plant Biology, 10(6) pp 587-593

Borgerding, M., \& Klus, H. (2005) Analysis of complex mixtures--cigarette smoke. Exp Toxicol Pathol, 57(1) pp 43-73.

Bhalerao, R., Keskitalo, J., Sterky, F., Erlandsson, R., Björkbacka, H., Birve, S. J., Karlsson, J., Gardeström, P., Gustafsson, P., Lundeberg, J. \& Jansson, S. (2003) Gene expression in autumn leaves. Plant Physiology, 131(2) pp 430-442. 
British American Tobacco (n.d.) Available from www.BAT-science.com

Buchanan-Wollaston, V. \& Ainsworth, C. (1997) Leaf senescence in Brassica napus: cloning of senescence related genes by subtractive hybridisation. Plant Molecular Biology, 33(5) pp 821-834

Buchanan-Wollaston, V., Page, T., Harrison, E., Breeze, E., Lim, P. O., Nam, H. G., Lin, J. F., $\mathrm{Wu}$, S. H., Swidzinski, J., Ishizaki, K. \& Leaver, C. J. (2005) Comparative transcriptome analysis reveals significant differences in gene expression and signalling pathways between developmental and dark/starvation-induced senescence in Arabidopsis, Plant Journal, 42 pp 567-585

Burton, H. R., Bush, L. P. \& Djordjevic, M. V., (1989) Influence of temperature and humidity on the accumulation of tobacco-specific nitrosamines in stored burley tobacco. Journal of Agriculture Food Chemistry 37, pp 1372-1377

Burton, H. R., Dye, N. K. \& Bush, L. P., (1994) Relationship between Tobacco-Specific Nitrosamines and Nitrite from Different Air-Cured Tobacco Varieties. Journal of Agriculture Food Chemistry 42 (9), pp 2007-2011

Causier, B., Kieffer, M., Davies, B. (2002) Plant biology. MADS-box genes reach maturity, Science, 296(5566) pp275-276.

Comai, L., Dietrich, R. A., Maslyar, D. J., Baden, F. S. \& Harada, J. J., Coordinate expression of transcriptionally regulated isocitrate lyase and malate synthase genes in Brassica napus L., Plant Cell, 1989, 1(3) pp 293-300

Coque, M., Martin, A., Veyrieras, J. B., Hirel, B. \& Gallais, A. (2008) Genetic variation for Nremobilization and postsilking $\mathrm{N}$-uptake in a set of maize recombinant inbred lines. 3. QTL detection and coincidences, Theoretical and Applied Genetics, 117(5) pp 729747

Chung, T., Suttangkakul, A. \& Vierstra, R. D. (2009) The ATG autophagic conjugation system in maize: ATG transcripts and abundance of the ATG8-lipid adduct are regulated by development and nutrient availability, Plant Physiology 149, pp220234

Day, A. \& Goldschmidt-Clermont, M. (2011) The chloroplast transformation toolbox: selectable markers and marker removal Plant Biotechnology Journal 9 (5) pp 540-553

Dodd, A., Salathia, N., Hall, A., Kévei, E., Tóth, R., Nagy, F., Hibberd, J. M., Millar, A. J. \& Webb, A. A. R. (2005), Plant Circadian Clocks Increase Photosynthesis, Growth, Survival, and Competitive Advantage. Science 309(5734) pp 630-633

Davis, L. D. \& Neilsen, M (1999) Tobacco Production Chemistry Technology, Blackwell Science Ltd., ISBN 0-632-04791-7, Oxford

Edwards K. D., Bombarely, A., Story, G. W., Allen, F., Mueller, L. A., Coates, S. A., Jones, L. (2010) TobEA: an atlas of tobacco gene expression from seed to senescence, $B M C$ Genomics, 11:142.

Edwards, K., Anderson, P., Hall, A., Salathia, N., Locke, J., Lynn, J., Straume, M., Smith, J. \& Millar, A. (2006) FLOWERING LOCUS C Mediates Natural Variation in the HighTemperature Response of the Arabidopsis Circadian Clock, Plant Cell, 18 pp 639650

Feys B.J., Wiermer, M., Bhat, R. A., Moisan, L. J., Medina-Escobar, N., Neu, C., Cabral, A. \& Parker, J. E. (2005) Arabidopsis SENESCENCE-ASSOCIATED GENE101 stabilizes and signals within an ENHANCED DISEASE SUSCEPTIBILITY1 complex in plant innate immunity. Plant Cell, 17(9) pp 2601-2613 
Fischer, S., Spiegelhalder, B. \& Preussmann, R. (1989) Preformed tobacco-specific nitrosamines in tobacco - role of nitrate and influence of tobacco type, Carcinogenesis, 10 pp1511-1517

Fracheboud, Y., Luquez, V., Björkén, L., Sjödin, A., Tuominen, H. \& Jansson S. (2009) The control of autumn senescence in European aspen, Plant Physiology, 149(4) pp 19821891

Friedrich, J. W. \& Huffaker, R. C. (1980) Photosynthesis, leaf resistances, and ribulose-1,5bisphosphate carboxylase degradation in senescing barley leaves, Plant Physiology, 65(6) pp 1103-1107

Gan, S. \& Amasino, R. M., (1995) Inhibition of Leaf Senescence by Autoregulated Production of Cytokinin, Science 270(5244) pp 1986-1988

Ghosh, S., Meli, V., Kumar, S., Thakur, A., Chakraborty, N., Chakraborty, S. \& Datta, A. (2011) The N-glycan processing enzymes a-mannosidase and $\beta$-D-Nacetylhexosaminidase are involved in ripening-associated softening in the nonclimacteric fruits of capsicum, Journal of Experimetal Botany 62(2) pp 571-582

Grbic, V. \& Bleecker, A. (1995) Ethylene regulates the timing of leaf senescence in Aradopsis. The Plant Journal, 8(4) pp 595-602

Gepstein, S., Sabehi, G., Carp, M. J. T. H., Falah, M., Nesher, O., Yariv, I., Dor, C. \& Bassani, M. (2003) Large-scale identification of leaf senescence-associated genes. The Plant Journal 36 pp 629-642

Gregersen, P. L. \& Holm, P. B. (2007) Transcriptome analysis of senescence in the flag leaf of wheat (Triticum aestivum L.), Plant Biotechnology Journal 5(1) pp 192-206.

Gregersen, P. L., Holm, P. B. \& Krupinska, K. (2008) Leaf senescence and nutrient remobilisation in barley and Wheat, Plant Biology, 10 pp 37-49

Griffith, C. M., Hosken, S. E., Oliver, D., Chojecki, J. \& Thomas, H. (1997) Leaf senescence: Physiology and molecular biology, Plant Molecular Biology, 34 pp 815-821

Guo, Y. \& Gan, S. (2005) Leaf Senescence: Signals, Execution, and Regulation Current Topics in Developmental Biology. 71 pp 83-112

Guo, Y., Cai, Z. \& Gan, S. (2004) Transcriptome of Arabidopsis leaf senescence. Plant Cell $\mathcal{E}$ Environment 27 pp 521-549

Harmer, S. L., Hogenesch, J. B., Straume, M., Chang, H. S., Han, B., Zhu, T., Wang, X., Kreps, J. A. \& Kay, S, A. (2000) Orchestrated transcription of key pathways in Arabidopsis by the circadian clock. Science 290(5499) pp 2110-2113

Harrington, G. \& Bush, D. (2003) The Bifunctional Role of Hexokinase in Metabolism and Glucose Signaling, Plant Cell, 15(11) pp 2493-2496

Haussühl, K., Andersson, B. \& Adamska, I. (2001) A chloroplast DegP2 protease performs the primary cleavage of the photodamaged D1 protein in plant photosystem II. EMBO Journal 20 pp 713-722

He, Y. \& Gan, S. (2002) A gene encoding an acyl hydrolase is involved in leaf senescence in Arabidopsis, Plant Cell, 14(4) pp 805-815

He, Y., Tangm, W., Swain, J. D., Green, A. L., Jack, T. P. \& Gan, S. (2001) Networking Senescence-Regulating Pathways by Using Arabidopsis Enhancer Trap Lines, Plant Physiology, 126 pp 707-716

Hensel, L. L., Garbic, V., Baumgarten, D. A. \& Bleecker, A. B., (1993) Leaf senescence: Physiology and molecular biology. Plant Cell, 5 pp 553-564. 
Hoffmann, D. \& Wynder, E. L. (1967) The reduction of the tumorigenicity of cigarette smoke condensate by addition of sodium nitrate to tobacco, Cancer Research, 27(1) pp 172174

Hopkins, M., Taylor, C., Liu, Z., Ma, F., McNamara, L., Wang, T. W. \& Thompson, J. E. (2007) Regulation and execution of molecular disassembly and catabolism during senescence. New Phytologist. 175 pp 201-214

Hörtensteiner, S. (2006) Chlorophyll degradation during senescence. Annual Reviews in Plant Biology 57 pp 55-77

Hörtensteiner, S. \& Feller, U. (2002) Nitrogen metabolism and remobilization during senescence, Journal of Experimental Botany 53(370) pp 927-37

Jackson, S. D. (2009) Plant responses to photoperiod, New Phytologist, 181(3) pp 517-531

Klee, H. J. (2010) Improving Flavor of Fresh Fruits: Genomics biochemistry and biotechnology New Phytologist, 187(1) pp 44-56

Kim, D. J. \& Smith, S. M. (1994) Molecular cloning of cucumber phosphoenolpyruvate carboxykinase and developmental regulation of gene expression, Plant Molecular Biology, 26 pp 423-434

Labboun, S., Tercé-Laforgue, T., Roscher, A., Bedu, M., Restivo, F. M., Velanis, C. N., Skopelitis, D. S., Moschou, P. N., Roubelakis-Angelakis, K. A., Suzuki, A. \& Hirel, B. (2009) Resolving the role of plant glutamate dehydrogenase. I. In vivo real time nuclear magnetic resonance spectroscopy experiments. Plant Cell Physiology, 50(10) pp 1761-1773

Lea, P. J. \& Miflin, B. J., (1974) Alternative route for nitrogen assimilation in higher plants. Nature. 251(5476) pp 614-616

Lim, P. O., Kim, H. J. \& Nam, H. G. (2007) Leaf senescence. Annual Review of Plant Biology. 58 pp 115-136

Lin, J. F. \& Wu, S. H. (2004) Molecular events in senescing Arabidopsis leaves, Plant Journal, 39(4) pp612-628

Lohman, K., Gan, S., John, M. \& Amasino, R. M. (1994) Molecular analysis of natural leaf senescence in Arabidopsis thaliana, Physiologia Plantarum, 92 pp 322-328

Lossl, A. \& Waheed, M. (2011) Chloroplast-derived vaccines against human diseases: achievements, challenges and scopes, Plant Biotechnology Journal, 9 pp 527-539

Mae, T., Kai, N., Makino, A. \& Ohira, K. (1984) Relation between ribulose bisphosphate carboxylase content and chloroplast number in naturally senescing primary leaves of wheat. Plant Cell \& Physiology, 25 pp 333-336

Masclaux, C., Valadier, M. H., Brugière, N., Morot-Gaudry, J. F. \& Hirel, B. (2000) Characterization of the sink/source transition in tobacco (Nicotiana tabacum L.) shoots in relation to nitrogen management and leaf senescence, Planta, 211(4) pp 510-518

Morris, K., MacKerness, S. A., Page, T., John, C. F., Murphy, A. M., Carr, J. P. \& BuchananWollaston, V. (2000) Salicylic acid has a role in regulating gene expression during leaf senescence, Plant Journal, 23(5) pp 677-685

Mueller, L. A., Solow, T. H., Taylor, N., Skwarecki, B., Buels, R., Binns, J., Lin, C., Wright, M. H., Ahrens, R., Wang, Y., Herbst, E. V., Keyder, E. R., Menda, N., Zamir, D. \& Tanksley, S. D. (2005) The SOL Genomics Network. A Comparative Resource for Solanaceae Biology and Beyond. Plant Physiol. 138(3) pp 1310-1317.

Noodén, L. D., Guiamét, J. J. \& John, I. (1997) Senescence mechanisms, Physiologia Plantarum, 101 pp 746-753 
Otegui, M. S., Noh, Y. S., Martínez, D. E., Vila Petroff, M. G., Staehelin, L. A., Amasino \& R. M., Guiamet, J. J. (2005) Senescence-associated vacuoles with intense proteolytic activity develop in leaves of Arabidopsis and soybean. Plant Journal, 41(6) pp 831844

Norman, A. (1999). Cigarette Design and Materials. In: Tobacco Producton, Chemistry and Technology, Davis D L \& Nielsen M. T., pp. 353-387, Blackwell Science Ltd., ISBN 0632-04791-7, Oxford

Ohsumi, Y. (2001) Molecular mechanism of bulk protein degradation in lysosome/vacuole, Tanpakushitsu Kakusan Koso, 46(11) pp 1710-1716

Pruzinska, A., Tanner, G., Aubry, S., Anders, I., Moser, S., Muller, T., Ongania, K. H., Krautler, B., Youn, J. Y., Liljegren, S. J. \& Hortensteiner, S. (2005) Chlorophyll Breakdown in Senescent Arabidopsis Leaves. Characterization of Chlorophyll Catabolites and of Chlorophyll Catabolic Enzymes Involved in the Degreening Reaction. Plant Physiology, 139 pp 52-63

Quirino, B. F., Normanly, J. \& Amasino, R. M. (1999) Diverse range of gene activity during Arabidopsis thaliana leaf senescence includes pathogen-independent induction of defense-related genes. Plant Molecular Biology, 40(2) pp 267-278.

Rodgman, A. \& Perfetti, T. A. (2009) The chemical components of tobacco and tobacco smoke. CRC press, Florida, USA. pp 1259. ISBN 978-1-4200-7883-1.

Shaul, O. \& Galili, G. (1993) Concerted regulation of lysine and threonine synthesis in tobacco plants expressing bacterial feedback-insensitive aspartate kinase and dihydrodipicolinate synthase. Plant Molecular Biology, 23(4) pp 759-768.

Smart, C. M. (1994) Gene expression during leaf senescence. New Phytologist 126 pp 419-448

Sokolenko, A., Lerbs-Mache, S., Altschmied, L., Herrmann, R. G. (1998) Clp protease complexes and their diversity in chloroplasts. Planta, 207 pp 286-295

Spiegelhalder, B., Bartsch, H.(1996) Tobacco-specific nitrosamines, European Journal of Cancer Prevention, 5 pp 33-38

Stitt, M., Müller, C., Matt, P., Gibon, Y., Carillo, P., Morcuende, R., Scheible, W. R. \& Krapp, A. (2002) Steps towards an integrated view of nitrogen metabolism, Journal of Experimental Botany 53(370) pp 959-70

Thomas, H. \& Donnison, I. (2000) Back from the brink: plant senescence and its reversibility, Symposium Society of Experimental Biology, 52 pp 149-162

Thomas, H. \& Stoddart, J. L. (1980). Leaf senescence, Annual Review of Plant Physiology, 31 pp 83-111

Thompson, A. R. \& Vierstra, R. D. (2005) Autophagic recycling: lessons from yeast help define the process in plants, Current Opinions in Plant Biology, 8(2) pp 165-173

Tollenaar, M. \& Wu, J. (1999). Yield improvement in temperate maize is attributable to greater stress Tolerance, Crop Science, 39 pp 1597-1604

Uauy, C., Distelfeld, A., Fahima, T., Blechl, A. \& Dubcovsky J (2006) A NAC Gene regulating senescence improves grain protein, zinc, and iron content in wheat Science, 314(5803) pp 1298-1301

Van der Graaff, E., Schwacke, R., Schneider, A., Desimone, M., Flugge, U. I. \& Kunze, R. (2006) Transcription Analysis of Arabidopsis Membrane Transporters and Hormone Pathways during Developmental and Induced Leaf Senescence, Plant Physiology, 141 pp 776-792

Van Doorn, W. G. (2008) Is the onset of senescence in leaf cells of intact plants due to low or high sugar levels? Experimental Botany 59(8) pp 1963-1972 
Vierstra, R. D. (1996) Proteolysis in plants: mechanisms and functions. Plant Molecular Biology, 32(1-2) pp 275-302

Verburg, J. G., Huynh, Q.K. (1991) Purification and Characterization of an Antifungal Chitinase from Arabidopsis thaliana, Plant Physiology, 95(2) pp 450-455

Watanabe, A., Hamada, K., Yokoi, H. \& Watanabe, A., (1994) Biophysical and differential expression of cytosolic glutamine synthetase genes of radish during seed germination and senescence of cotyledons, Plant Molecular Biology, 26 pp 1807-1817

Weasel, L. H. (2009) Food Fray: Inside the Controversy over Genetically Modified Food, Amacom, ISBN-13: 978-0814401644, New York

Wingler, A. \& Roitsch, T. (2008) Metabolic regulation of leaf senescence: interactions of sugar signalling with biotic and abiotic stress responses, Plant Biology, 10 pp 50-62.

Wittenbach, V. A. (1978) Breakdown of Ribulose Bisphosphate Carboxylase and Change in Proteolytic Activity during Dark-induced Senescence of Wheat Seedlings, Plant Physiology, 62(4) pp 604-608

Wu, W., Zhang, L., Jain, R. B., Ashley, D. L. \& Watson, C. H. (2005) Determination of carcinogenic tobacco-specific nitrosamines in mainstream smoke from U.S.-brand and non-U.S.-brand cigarettes from 14 countries, Nicotine Tobacco Research, 7(3) pp $443-451$

Xue-Xuan, X., Hong-Bo, S., Yuan-Yuan, M., Gang, X., Jun-Na, S., Dong-Gang, G. \& ChengJiang, R. (2010) Biotechnological implications from abscisic acid (ABA) roles in cold stress and leaf senescence as an important signal for improving plant sustainable survival under abiotic-stressed conditions, Critical Reviews in Biotechnology, 30(3) pp 222-230

Yang, J. \& Zhang, J. (2006) Grain filling of cereals under soil drying, New Phytologist 169(2) pp 223-236

Yoshida, S. (2003) Molecular regulation of leaf senescence, Current opinion in plant biology, 6 pp 79-84

Zavaleta-Mancera, H. A., Thomas, B. J., Thomas, H. \& Scott, I. M. (1999) Regreening of senescent Nicotiana leaves, Journal of Experimental Botany, 50(340) pp 1683-1689 


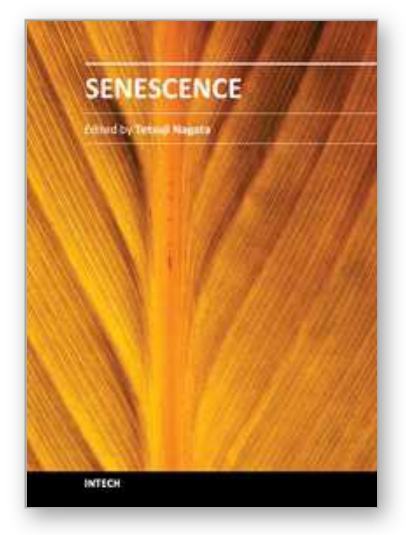

\author{
Senescence \\ Edited by Dr. Tetsuji Nagata
}

ISBN 978-953-51-0144-4

Hard cover, 850 pages

Publisher InTech

Published online 29, February, 2012

Published in print edition February, 2012

The book "Senescence" is aimed to describe all the phenomena related to aging and senescence of all forms of life on Earth, i.e. plants, animals and the human beings. The book contains 36 carefully reviewed chapters written by different authors, aiming to describe the aging and senescent changes of living creatures, i.e. plants and animals.

\title{
How to reference
}

In order to correctly reference this scholarly work, feel free to copy and paste the following:

Kieron D. Edwards, Matt Humphry and Juan Pablo Sanchez-Tamburrino (2012). Advances in Plant Senescence, Senescence, Dr. Tetsuji Nagata (Ed.), ISBN: 978-953-51-0144-4, InTech, Available from: http://www.intechopen.com/books/senescence/advances-in-plant-senescence

\section{INTECH}

open science | open minds

\section{InTech Europe}

University Campus STeP Ri

Slavka Krautzeka 83/A

51000 Rijeka, Croatia

Phone: +385 (51) 770447

Fax: +385 (51) 686166

www.intechopen.com

\section{InTech China}

Unit 405, Office Block, Hotel Equatorial Shanghai

No.65, Yan An Road (West), Shanghai, 200040, China

中国上海市延安西路65号上海国际贵都大饭店办公楼405单元

Phone: +86-21-62489820

Fax: +86-21-62489821 
(C) 2012 The Author(s). Licensee IntechOpen. This is an open access article distributed under the terms of the Creative Commons Attribution 3.0 License, which permits unrestricted use, distribution, and reproduction in any medium, provided the original work is properly cited. 